\title{
Involuntary stabilization care of youth who overdose: a call for evidence- and ethics-informed substance use policy
}

\author{
Trevor Goodyear $^{1,2,3}$ (D) Samantha Robinson ${ }^{1,2} \cdot$ Emily Jenkins $^{1} \cdot$ Marilou Gagnon ${ }^{4} \cdot$ Keren Mitchell $^{1,5,6,7}$. \\ Rod Knight ${ }^{2,8}$
}

Received: 12 September 2020 / Accepted: 24 November 2020 / Published online: 11 January 2021

(C) The Canadian Public Health Association 2021

\begin{abstract}
As is the case across Canada, the province of British Columbia is in the midst of an opioid overdose crisis. In response to the devastating impacts of this crisis on youth (under 19 years of age), the provincial government is considering amending the Mental Health Act to allow for involuntary, hospital-based stabilization care of youth following an overdose. This policy change represents one concrete action that the provincial government is exploring in response to public advocacy for enhanced supports for youth who overdose. At this juncture, however, we are concerned that stabilization care requires further interrogation in the context of key, interrelated public health and ethical dimensions pertaining to this legislation. In this commentary, we describe three key areas for public health deliberation: (1) the evidence underpinning stabilization care, (2) ethical considerations, and (3) the potential for unintended and unevenly distributed consequences. We then offer ways forward to guide and provide opportunities for a more equitable public health response to the overdose crisis and its impacts on youth. In doing so, we emphasize the need for meaningful engagement of youth as key stakeholders in the development of evidence- and ethics-informed substance use care and policy interventions.
\end{abstract}

\section{Résumé}

Comme le reste du Canada, la province de la Colombie-Britannique est en pleine crise de surdoses d'opioïdes. En réponse aux effets dévastateurs de cette crise sur les jeunes (moins de 19 ans), le gouvernement provincial songe à modifier la loi sur la santé mentale de la province pour permettre les soins de stabilisation forcés des jeunes à l'hôpital après une surdose. Ce changement d'orientation représente une mesure concrète envisagée en réaction aux campagnes de sensibilisation qui préconisent des mesures de soutien améliorées aux jeunes qui font des surdoses. À ce stade toutefois, nous pensons que les soins de stabilisation nécessitent une interrogation plus poussée sur les aspects sanitaires et éthiques essentiels et interdépendants afférents à cette loi. Dans notre commentaire, nous décrivons trois aspects clés des délibérations de la santé publique : 1) les données probantes qui sous-tendent les soins de stabilisation, 2) les considérations éthiques et 3) les effets pervers et inégalement répartis qui pourraient en découler. Nous proposons ensuite une marche à suivre pour guider et créer les possibilités d'une riposte plus équitable de la santé publique à la crise des surdoses et à ses répercussions sur les jeunes. Ce faisant, nous insistons sur la nécessité de faire participer concrètement les jeunes, en tant qu'acteurs privilégiés, à l'élaboration d'interventions de soins et de politiques sur la consommation de substances éclairées par les données probantes et par l'éthique.

Keywords Youth $\cdot$ Substance use $\cdot$ Overdose $\cdot$ Opioid $\cdot$ Health policy $\cdot$ Ethics

Mots-clés Jeunes $\cdot$ consommation de substances $\cdot$ surdose $\cdot$ opioïde $\cdot$ politique de santé $\cdot$ éthique

Trevor Goodyear

trevor.goodyear@bccsu.ubc.ca

1 School of Nursing, University of British Columbia, Vancouver, BC, Canada

2 British Columbia Centre on Substance Use, 400-1045 Howe St, Vancouver, BC V6Z 2A9, Canada

3 Healthy Minds Centre, British Columbia Children's Hospital, Vancouver, Canada
4 Canadian Institute for Substance Use Research, University of Victoria, Victoria, BC, Canada

5 Faculty of Health Studies, Brandon University, Brandon, MB, Canada

6 Inner City Youth Program, Providence Health Care, Vancouver, Canada

7 Foundry, Vancouver, Canada

8 Department of Medicine, University of British Columbia, Vancouver, Canada 


\section{Introduction}

In Canada and internationally, fentanyl-adulterated illicit drug markets have led to stark increases in overdoses and overdose deaths, including among youth. The Canadian province of British Columbia (BC) is among the hardest hit by the overdose crisis (British Columbia Coroners Service 2020). Since 2016, more than 5000 people have died of an overdose in BC, including 81 youth under the age of majority (19 years) - and this death toll is now skyrocketing in conjunction with the COVID-19 pandemic (British Columbia Coroners Service 2020). Provincial public health responses to this crisis have expanded access to effective and much-needed post-overdose supports, including opioid agonist treatment (OAT) and voluntary substance use assessment and treatment services (British Columbia Ministry of Mental Health and Addictions 2019). The $B C$ government is now also considering amending the Mental Health Act to allow for involuntary, hospital-based stabilization care (hereafter referred to as "stabilization care") of youth following an overdose (British Columbia Ministry of Mental Health and Addictions 2020). This policy issue, like many other issues related to substance use and/or youth, is highly politicized. Some stakeholders, including parents of youth who have overdosed and policy decision-makers, may be in favour of stabilization care as a measure that they believe will keep youth safe. There may also be the view that alternative, harm-reduction-oriented responses to the overdose crisis (e.g., safer drug supply) are "enabling" to those who use drugs. Indeed, there has already been significant public health debate related to the acceptability of stabilization care, leading BC's legislative amendments to be placed on "pause" pending further stakeholder consultation (Zeidler 2020). At this juncture, we propose that stabilization care be further interrogated in the context of key, interrelated public health and ethical dimensions pertaining to this legislation.

\section{Stabilization care in Canada}

The implementation of and limited evidentiary support for stabilization care are cause for significant public health concern. Models of "secure" or mandated care have already been implemented in provinces across Canada, particularly in youth justice system contexts, including jails and courtmandated substance use treatment programs (Pilarinos et al. 2018). Existing secure care models have garnered both critique and endorsement from key stakeholders related to youth substance use policy, including parents and clinicians (Hamilton et al. 2019; Weiz 2020). We therefore anticipate that stakeholder groups from across Canada, including in provinces and territories where there is political momentum to implement secure care measures, will be closely monitoring if, how, and with what outcomes BC's approach to this policy unfolds. BC's model would be implemented through Mental Health Act amendments that allow hospitals to forcibly admit youth for stabilization (i.e., "detoxification") care for up to seven days following an overdose (British Columbia Ministry of Mental Health and Addictions 2020). Specific and transparent details on what this stabilization care would entail, or how the interventions used in this model would differ from those used in secure care contexts, are scarcely documented in publicly available provincial policy documents. Details of this nature are urgently needed to more fulsomely contextualize and evaluate the appropriateness of stabilization care in BC. Nonetheless, from our research and clinical experiences with youth who use drugs, we know that the spectrum of stabilization and/or secure care could include, for example, mandatory assessments, counselling, and linkage to community health services, as well as voluntary provision of OAT. Youth experiencing stabilization care may also face denial of access to essential harm-reduction supplies, body and room searches (i.e., for substances), and, potentially, physical and chemical restraints. A subset of these interventions (e.g., OAT, linkage to services) can be highly effective at promoting long-term engagement of youth in substance use treatment when implemented in voluntary treatment settings. Yet, there is limited to no empirical evidence to support the effectiveness of this intervention spectrum when used without full, informed consent. Indeed, as argued in detail by our colleagues (DeBeck et al. 2019; Pilarinos et al. 2018), while the "burden of proof" should rest on establishing that secure and/ or stabilization care is safe and effective, scientifically credible data of this nature are not currently available.

\section{Ethics and unintended consequences of stabilization care}

The ethics of stabilization and/or secure care further underscore a need for caution related to its implementation (Clark et al. 2019). From a public health ethics standpoint, the more coercive and intrusive an intervention (i.e., the extent to which it infringes upon individual liberties, including competent choice), the more it necessitates strong empirical and ethical substantiation to be considered justifiable (Nuffield Council on Bioethics 2007). Yet, the empirical evidence related to the effectiveness of stabilization care is of poor quality, and this intervention has the very real potential to violate a number of ethical principles. For example, stabilization care interventions and the contexts in which they would be implemented (locked psychiatric units and emergency rooms - likely in adult hospitals, due to the lack of pediatric hospitals across $\mathrm{BC}$ ) greatly reduce youth's liberty and autonomy to consent via highly restrictive and coercive actions. This undermining of youths' decision-making capacity in substance use care - where youth may already be characterized as lacking in autonomy, due to 
paternalistic assumptions related to addiction and age - is both unwarranted and ethically problematic. This is particularly so in this setting, where other, less restrictive, ethical interventions are available to support the health and well-being of youth who use drugs, including drug-checking technologies, supervised consumption services, and voluntary substance use treatment. As is the case with other adolescent health issues (e.g., contraception, suicidality), supportive healthcare and family approaches that actively engage youth as participants in their care-rather than coercive and enforcement-oriented interventions - are most needed.

If implemented in $\mathrm{BC}$, we are highly concerned that the potential harms associated with stabilization and/or secure care may outweigh its benefits. It is well documented that rapidwithdrawal and abstinence-focused treatments among adults lower one's opioid tolerance, which, given the high incidence of post-treatment relapse among people who use drugs, poses significant risk for (re)experiencing an overdose (Pilarinos et al. 2018; Srivastava et al. 2017). This issue is also relevant to youth who use drugs, as is reflected in BC's Chief Coroner's statement in response to stabilization care legislation (British Columbia Government News 2020). Of further concern, stabilization care risks jeopardizing access to healthcare. Within our own programs of research and clinical practice, youth frequently tell us that they actively avoid services, care providers, and/ or peer and family supports that they experience as or perceive to be coercive. Taking this into account, stabilization care risks undermining clinician-client and family-child relationships, along with the linkages to supports that youth may benefit from most, including harm reduction and voluntary substance use treatment and care (Pilarinos et al. 2018). Moreover, fear of and/or experiences with stabilization care may deter youth from future engagement with the health care system, including calling 911 in the event of an overdose, due to concerns over potential (re)apprehension. Given the severity of the overdose crisis, and given that concerns about policing and enforcement are already known to deter people from seeking emergency help following an overdose (Karamouzian et al. 2019), the need to maintain youth engagement and trust in healthcare services is paramount.

Like all public health interventions, the effects (both positive and negative) of stabilization care will also be inequitably distributed along a social gradient, with socially marginalized subgroups of youth experiencing the worst social and health outcomes. Unfortunately, it is well documented that intersecting forms of stigma and discrimination, including those related to substance use, are pervasive within the Canadian healthcare system (Public Health Agency of Canada 2019). And while substance use stigma may harm all youth in stabilization care, key subpopulations of youth (e.g., those who are structurally vulnerable due to indigeneity, racialization, LGBTQ2+ identity, or involvement with the child welfare system) are likely to face additional and heightened harms. Given healthcare access inequities faced, we urge proponents of stabilization care to consider the potential for inadvertent and unevenly distributed harms.

\section{Future directions in youth substance use care and policy}

The unprecedented morbidity and mortality associated with BC's overdose crisis warrants immediate and concerted public health action. This must include judicious use of effective and ethically sound substance use care and policy interventions, as well as capacity- and coalition-building efforts to ensure their successful implementation. Ultimately, stabilization care measures do not satisfy the burden of proof of both empirics and ethics and, further, risk undermining youth autonomy and engagement in care. Now, more than ever, there is a critical demand for sensible healthcare and public policies that resonate with youth and that have been demonstrated to mitigate risk of drug-related harms, including overdose. Accordingly, we call for the meaningful engagement of youth who use drugs as key stakeholders in all phases of substance use policy discussions and decision-making processes. Moreover, to mobilize these policy discussions into action, we call upon health systems and service providers to decisively advocate for and champion evidence- and ethics-informed interventions that directly reflect the needs and experiences of youth who use drugs.

Funding TG receives trainee support through the Canadian Nurses Foundation and the US National Institute of Drug Abuse (Grant R25DA033756). RK and EJ are supported by Scholar Awards from the Michael Smith Foundation for Health Research.

\section{Compliance with ethical standards}

Conflict of interest The authors declare that they have no conflict of interest.

\section{References}

British Columbia Coroners Service. (2020). Illicit drug toxicity deaths in British Columbia: January 1, 2010-September 30, 2020. Retrieved November 5, 2020, from https://www2.gov.bc.ca/assets/gov/birthadoption-death-marriage-and-divorce/deaths/coroners-service/ statistical/illicit-drug.pdf.

British Columbia Government News. (2020). Chief coroner's statement on proposed amendments to the Mental Health Act [Press release]. Retrieved September 12, 2020, from https://news.gov.bc.ca/ releases/2020PSSG0035-001150.

British Columbia Ministry of Mental Health and Addictions. (2019). Escalating BC's response to the overdose emergency. Retrieved November 5, 2020, from https://www2.gov.bc.ca/assets/gov/ overdose-awareness/mmha escalating bcs response report final 26feb.pdf.

British Columbia Ministry of Mental Health and Addictions. (2020). Stabilization care proposed for youth following an overdose [Press 
release]. Retrieved September 12, 2020, from https://news.gov.bc. ca/releases/2020MMHA0032-001139.

Clark, B. A., Preto, N., Everett, B., Young, J., \& Virani, A. (2019). An ethical perspective on the use of secure care for youth with severe substance use. Canadian Medical Association Journal, 191(7), E195-E196. https://doi.org/10.1503/cmaj.71504.

DeBeck, K., Kendall, P., Fast, D., \& Pilarinos, A. (2019). The authors respond to comments on the use of secure care in youth. Canadian Medical Association Journal, 191(7), E199-E200. https://doi.org/ 10.1503/cmaj.71589.

Hamilton, A. L., Jarvis, D. G., \& Watts, B. E. L. (2019). RE: Secure care: more harm than good (1) (the commentary) and reply to letters to the commentary (2) (the reply). Canadian Medical Association Journal, 190(41). https://doi.org/10.1503/cmaj.180700.

Karamouzian, M., Kuo, M., Crabtree, A., \& Buxton, J. A. (2019). Correlates of seeking emergency medical help in the event of an overdose in British Columbia, Canada: findings from the Take Home Naloxone program. The International Journal on Drug Policy, 71, 157-163. https://doi.org/10.1016/j.drugpo.2019.01.006.

Nuffield Council on Bioethics. (2007). Public health: ethical issues. London: Cambridge Publishers Ltd.

Pilarinos, A., Fast, D., DeBeck, K., \& Kendall, P. (2018). Secure care: more harm than good. Canadian Medical Association Journal, 190(41), E1219-E1220. https://doi.org/10.1503/cmaj.180700.
Public Health Agency of Canada. (2019). Addressing stigma: towards a more inclusive health system. The Chief Public Health Officer's report on the state of public health in Canada 2019. Retrieved September 12, 2020, from Ottawa, ON: https://www.canada.ca/ content/dam/phac-aspc/documents/corporate/publications/chiefpublic-health-officer-reports-state-public-health-canada/addressingstigma-what-we-heard/stigma-eng.pdf.

Srivastava, A., Kahan, M., \& Nader, M. (2017). Primary care management of opioid use disorders: abstinence, methadone, or buprenorphine-naloxone? Canadian Family Physician, 63(3), 200-205

Weiz, A. (2020). The trouble with PChAD (The Protection of Children Abusing Drugs Act in Alberta). Retrieved November 5, 2020, from https://www.momsstoptheharm.com/personal-blog/2020/1/27/thetrouble-with-pchad.

Zeidler, M. (2020). Province hits pause on controversial bill that would allow involuntary hospitalization of youth who overdose. Canadian Broadcasting Corporation. Retrieved August 17, 2020, from https:// www.cbc.ca/news/canada/british-columbia/bill-22-bc-mentalhealth-act-1.5663935.

Publisher's note Springer Nature remains neutral with regard to jurisdictional claims in published maps and institutional affiliations. 